revista do ieb n 46 p. 165-178 fev 2008

\title{
Representações da natureza: mapas e gravuras produzidos durante o domínio neerlandês no Brasil (1624/1654)
}

Heloisa Meireles Gesteira ${ }^{1}$

Resumo

Os descobrimentos e a conquista do Novo Mundo provocaram um aumento do interesse em relação aos produtos "exóticos" que a partir do século XVI passaram, cada vez mais, a fazer parte das coleções européias, surgindo em jardins botânicos e gabinetes de curiosidades. Neste artigo analisaremos mapas e gravuras produzidos durante o domínio holandês como sintese deste movimento, uma vez que, além de demarcarem um território, nos oferecem uma descrição minuciosa do mesmo, contendo referências aos elementos da natureza e também aos habitantes, transformando-se ao um tempo em meio de difusão de conhecimento e obra de arte. A presença neerlandesa no Brasil durante o século XVII, embora efêmera, nos legou um manancial de informações sobre a região e ainda hoje formam um conjunto rico de textos e de iconografia que ajudam a fixar a imagem do Brasil holandês como um espaço privilegiado para o desenvolvimento ciência e da arte em solo americano, especialmente na cidade Maurícia.

\section{Palavras-chave}

História natural, Brasil-holandês, coleções, colonialismo 
revista do ieb n 46 p. 165-178 fev 2008

\title{
Representations of nature: maps and engravings produced during the Dutch rule in Brazil (1624/1654)
}

Heloisa Meireles Gesteira

\begin{abstract}
The discoveries and conquest of the New World spawned an icrease in interest for the "exotic" products which, from the sixteenth century onwards, became part of the European collections appearing in botanical gardens and curiosity cabinets. This paper shall analyse maps and engravings produced during the Dutch rule as an attempt to synthesize the period since they offer delimitations as well as detailed illustrations of the territory, including references to nature and the inhabitants, and serve as both source of information and works of art. The Dutch presence in Brazil during the seventeenth century, though short, left us a treasure trove of data about the region, which amounts to a rich body of texts and iconography, offering us a picture of how priviledged a space Dutch Brazil was for the development of the sciences and the arts on American ground, specially in the city governed by Maurits Van Nassau.
\end{abstract}

\section{Keywords}

Natural history, Dutch-Brazil, colletcions, colonialism 
Os descobrimentos e a conquista do Novo Mundo provocaram um aumento do interesse em relação aos produtos “exóticos” que a partir do século XVI passaram, cada vez mais, a fazer parte das coleções européias, surgindo em jardins botânicos e gabinetes de curiosidades. As pinturas e gravuras também contribuíam para a divulgação de imagens relativas às plantas e aos animais da América, especialmente em livros que tratavam de História Natural e mapas do Novo Mundo que circulavam na Europa. 0 conhecimento sobre a região a ser dominada, adquirido através do mapeamento, do registro do clima, dos produtos e dos habitantes, era um mecanismo de conquista de novas terras. Neste artigo analisaremos mapas e gravuras produzidos durante o domínio holandês como síntese deste movimento, uma vez que, além de demarcarem um território, nos oferecem uma descrição minuciosa do mesmo, contendo referências aos elementos da natureza e também aos habitantes, transformando-se a um só tempo em meio de difusão de conhecimento e obra de arte. A presença neerlandesa no Brasil durante o século XVII, embora efêmera, nos legou um manancial de informações sobre a região e ainda hoje formam um conjunto rico de textos e de iconografia que ajuda a fixar a imagem do Brasil holandês como um espaço privilegiado para o desenvolvimento ciência e da arte em solo americano, especialmente na cidade Maurícia.

Consideramos "coleção de Nassau” os objetos relacionados ao Brasil que permaneceram sob sua guarda e o conjunto das obras por ele patrocinadas, direta ou indiretamente, e também as realizadas tanto durante os anos de seu governo no Recife, como depois de seu retorno à República das Províncias Unidas ${ }^{2}$. Como exemplo cito os livros de História Natural de Guilherme Piso e Georg Marcgrave, Historia Naturalis Brasiliae, de 1648, e o fascinante livro de memórias de Nassau escrito pelo humanista Gaspar Barléus, Rerum per octennium in Brasilia et alibi nuper gestarum, sub praefectura Illustrissimi Comitis I Mauritti, Nassoviae (1647), onde se encontram 27 gravuras assinadas por

2 É comum fazer referência à República pela sua parte mais próspera, a Província da Holanda, onde se localiza a cidade de Amsterdam. Neste trabalho tomaremos o cuidado de sempre que mencionar o país fazê-lo da forma que especifiquemos apenas as províncias do norte dos Países Baixos que ficaram independentes do império espanhol em fins do século XVI, por isso Países Baixos Unidos, o que exclui todo o sul da região, pois essa área continuou sob tutela espanhola. Aos habitantes chamaremos neerlandeses e não holandeses. Nos permitiremos, no entanto, fazer referência ao termo consagrado Brasil Holandês para especificar a área da América portuguesa que foi tomada pelos batavos na primeira metade do século XVII, onde permaneceram de 1630 até 1654 . 
Frans Post e mapas atribuídos a Marcgrave. As obras mencionadas têm em comum o fato de terem sido elaborados a partir de material original entregue pelas mãos do Conde João Maurício de Nassau-Siegen aos respectivos autores e ou editores. Notese que no frontispício de Historia Naturalis (Fig. 1) destaca-se apenas o nome de Nassau, não havendo menção ao médico Guilherme Piso ou ao astrônomo Georg Marcgrave, responsáveis pela realização dos estudos in loco. Tampouco há referência a Johannes de Laet, diretor da Companhia das Índias Ocidentais e que ficou responsável pela organização desta obra, especialmente a parte atribuída a Marcgrave, que havia morrido durante viagem à região de Angola para onde se dirigiu quando deixou o Recife, sem nunca ter retornado à República.

Embora seja evidente o apoio do Conde às iniciativas acima mencionadas e o suporte que deu à produção artística e científica durante sua permanência no Recife, não identifico Nassau como um humanista, uma vez que sua atividade principal não eram as letras, e sim as armas. Como tantos expoentes da nobreza de sua época, que seguiram carreira militar e dirigiram tropas em períodos de guerra, Nassau teve uma formação educacional bastante aprimorada e, ao longo de sua vida, buscou ascensão e prestígio durante os tempos de paz. Afora o seu interesse pessoal, não esqueçamos que este foi um recurso muito utilizado por seus pares para conquistar respeito social e viver no estilo da nobreza da qual efetivamente ele fazia parte. Não é sem significado que o Conde presenteou homens ilustres com livros relacionados ao Brasil. Sabemos que encaminhou exemplares de Rerum per octennium in Brasília, de Barléus, a diversas cortes européias e que a sua coleção de pinturas, especialmente aquela atribuída ao pintor Albert Eckhout, foi doada ao Eleitor de Bradenburgo Frederico Guilherme, no ano de $1652^{3}$.

Valorizar apenas o mecenato de Nassau ofusca o papel importante de outros agentes sociais envolvidos com a produção e difusão de conhecimento adquirido pelos neerlandeses sobre o Brasil, e não ajudaria a explicar a potencialidade de circulação deste conhecimento, seja nos livros, seja por meio de gravuras avulsas, conforme nosso objetivo. Acreditamos que a conjunção de inúmeros fatores garantiu o acúmulo de informações sobre a

3 BOOGAART et al., Zo wijd de wereld strekt. Haia: De Stichting Johan Maurits van Nassau, 1980; STRAETEN, H. S. van der. Maurits de Braziliaan: het levensverhaal van Johan Maurits van Nassau-Siegen, stichter van het Muritshuis, gouverneur van Nederlands-Brazilie, Stadhouder van Kleef, 1604/1679. s. e., 1998; e MELLO, Evaldo Cabral. Nassau: Governador do Brasil Holandês. São Paulo: Companhia das Letras, 2006. 
fauna, a flora e a geografia americanas. A coleta de informações no Novo Mundo, a constituição de coleções de História Natural e a divulgação deste material não eram empreendimentos separados e contavam com o envolvimento de diversos agentes sociais: patrocinadores, sábios e editores. Some-se a isto os interesses de comerciantes em divulgar novos produtos no mercado Europeu. Ao escolhermos mapas como ponto de partida para nossa análise, é importante assinalar que entendemos estes documentos como meios privilegiados para fixar uma conquista política - o domínio da República das Províncias Unidas sobre uma região do Novo Mundo: o Brasil, tomado aos portugueses durante as guerras contra a monarquia espanhola - e como meio de difusão de imagens e saberes relativos à região ocupada, especialmente durante o governo do Conde João Maurício de Nassau-Siegen.

Para demonstrar o argumento utilizaremos a belíssima carta "Brasilia qua parte paret Belgis, [...] Brasilia Geographica e Hidrographica Tabula Nova. Contines Praefecturas de Cirii, cum Itapuama de Pernambuca, Itamaraca, Paraiba et Potigi vel Rio Graunde. Quam propriis observationibus ac dimensionibus diuturna peregrinatione a se habitis, fundamentaliter superstruebat et delineabat Georgius Marggraphius Germanus, Anno Christi 1643" (Fig. 2). 0 mapa foi editado por Johanes Blaeu, entre 1644 e 1646, e traz 1647 como data de publicação. Como indica a legenda, o mapa é atribuído ao astrônomo que acompanhou João Maurício de Nassau-Siegen ${ }^{4}$. Este documento permite-nos perceber não apenas a dimensão política da conquista neerlandesa por meio da produção cartográfica acerca do Brasil, mas revela também a força da História Natural no século XVII como meio de conhecimento e de fixação de imagens acerca dos lugares, sobretudo aqueles situados no Novo Mundo ${ }^{5}$. Além disso, um olhar atento para este documento permite identificar as várias etapas que contribuíram para sua confecção.

Comecemos pelo aspecto ligado mais diretamente à cartografia. A prioridade na produção de mapas acompanha a hegemonia no ultramar, o que só confirma a relação estreita entre a afirmação do poder dos estados europeus em terras distantes e a confecção de cartas, que quando publicadas, trans-

4 WHITEHEAD, P. J. P.; BOESMAN, M. Um retrato do Brasil holandês do século XVII: animais, plantas e gente pelos artistas de Johan Maurits de Nassau. Rio de Janeiro: Livraria Kosmos, 1989. p. 151.

5 CAPEL, Horacio Capel Saez. Ambientalismo e história. 0 Padre Las Casas

como geógrafo. In: América. Maringá: UDEM, 1999. 
formavam-se num instrumento de posse. No início do século XVII, o conhecimento adquirido pelos neerlandeses em relação ao ultramar sofreu uma transformação. No caso especifico da República, a produção artística e cultural acompanhou de perto a expansão marítima das Províncias Unidas, com mais razão ainda a cartografia. 0 conjunto de registros sobre a América que circulava na República estava estreitamente relacionado às investidas no Atlântico sob comando da Companhia das Índias 0cidentais ${ }^{6}$. Estes registros ao mesmo tempo em que funcionavam como um estímulo, eram enriquecidos à proporção que o processo de conquista se desenrolava. Se antes as informações eram adquiridas por meio de espionagem, compra ou devido à presença de neerlandeses em navios que levavam a bandeira de outros estados, especialmente Portugal, a partir da sua própria expansão ultramarina, os neerlandeses aumentaram seu acervo graças aos homens que empreenderam viagens exploratórias em navios com o pavilhão da República das Províncias Unidas.

0 ano de 1624 foi marcado pela primeira ofensiva neerlandesa visando ao estabelecimento de um entreposto batavo na América, mais precisamente na cidade de São Salvador, cravada na baía de Todos os Santos e sede da administração portuguesa na América. 0 ataque contou com o auxilio do Piloto Dierick Ruiters, autor de um famoso roteiro, Toortsee der zee-vaert (A Tocha da Navegação), publicado em 1623, que trazia informações sobre a costa brasileira, contendo planos dos principais portos. Apesar do fracasso da tentativa - um ano depois os neerlandeses foram expulsos da cidade - desde então, as visitas à costa americana não cessaram. No mesmo ano da investida contra São Salvador foi publicado um folheto em Amsterdam sob o título Diário de viagem e descrição do Brasil, Rio da Prata e Magalhães, onde se registra a situação dos países e cidades ${ }^{7}$. As informações contidas nesta publicação eram, em sua maioria, relativas às condições de navegação e aos aspectos econômicos de cada região, ou seja, nela prevaleciam notícias de natureza mercantil. Mapas, basicamente da costa, acompanhavam o texto, mostrando as principais cidades, portos e fortificações. As cartas eram ilustradas com cenas da vida e costumes locais, além de mostrar alguns produtos da natureza americana. Seja qual for o meio, a produção cartográfica neerlandesa acompanha de perto a

6 Doravante referida no texto por meio de sua sigla, WIC Westindische Compaignie.

7 Reys boeck van het rijk Brasilien, Rio de la Plata ende Magalhaes, daer in te sien is de gheleghentheyt van hare landen ende steden haren, Amsterdam, 1624. Biblioteca Nacional do Rio de Janeiro. 
afirmação da hegemonia das Províncias Unidas nas trocas internacionais, sendo Amsterdam o centro da "economia-mundo"8.

Desde a fundação da WIC em 1621, o conhecimento sobre a América aumentou consideravelmente o número de mapas, roteiros e cartas de marear trazendo informações precisas sobre a costa atlântica. Entretanto, como observou Jaime Cortesão em seu livro, História do Brasil nos Velhos Mapas, muitas das cartas neerlandesas foram confeccionadas a partir das técnicas e conhecimentos geográficos extraídos de fontes portuguesas. Em conseqüência disto, o autor considerou a cartografia produzida nos Países Baixos pelo seu aspecto meramente artístico e como resultado do desenvolvimento da técnica de gravuras na região, afirmando que elas "valem muito mais como obras de arte do que como documentos singulares para o conhecimento da história da geografia" e que as casas editoriais tiveram um papel maior do que os cartógrafos propriamente ditos na produção e divulgação de mapas na República das Províncias Unidas durante o século XVII 9

Passemos para a composição da carta Brasilia qua parte paret Belgis, [...] Brasilia Geographica e Hidrographica Tabula Nova. Entre outros motivos, atribui-se a carta a Marcgrave em decorrência dela ter sido composta a partir dos quatro mapas relativos às Capitanias conquistadas pelos neerlandeses e que ilustram o livro de Gaspar Barléus: Sergipe, Paraíba, Rio Grande, Pernambuco e Itamaracá (Fig. 3, 4, 5 e 6). 0 autor das memórias de Nassau informou que as cartas foram confeccionadas pelo jovem e que seriam até então as mais completas da região. Sabemos que o astrônomo realizou viagens ao interior da região sob governo neerlandês. A nomenclatura dos lugares e aspectos citados nos mapas varia entre o português e o holandês, o que pode indicar que Marcgrave tenha utilizado alguma fonte portuguesa, mas não obrigatoriamente, uma vez qua há notícia de que o astrônomo conhecia o idioma luso. E ainda que ele tenha utilizado alguma fonte para compor os seus mapas, isto não invalida o resultado, uma vez que era prática recorrente dos cartógrafos partir de uma matriz e ir acrescentando dados de acordo com a aquisição de novas informações, compondo novos mapas mais completos ${ }^{10}$.

8 BRAUDEL, Fernand. Civilização material e capitalismo: séculos XV ao XVIII. São Paulo: Martins Fontes, 1995. vol. 3, O tempo do mundo.

9 CORTESÃO, Jaime. História do Brasil nos velhos mapas. Rio de Janeiro: Instituto Rio Branco, Ministério das Relações Exteriores, s.d. p. 15.

10 Recentemente foram localizadas no Arquivo da Casa Real em Haia, Holanda, partes do diário de Marcgrave, onde o naturalista registrou a jornada que fez ao Ceará, entre julho e agosto de 1639. 
A semelhança entre as quatro gravuras acima mencionadas que ilustram o livro de Barléus e o Brasilia qua parte paret Belgis, [...] é evidente. Mas alguns comentários se fazem necessários. Em primeiro lugar lembremos que o livro de Barléus foi editado em 1647 pela tipografia dos Blaeu situada em Amsterdam e que, muito provavelmente, adquiriu a posse das gravuras publicadas no livro. No período da produção deste mapa, era comum o fato de os editores interferirem nas ilustrações de obras que saíam de suas respectivas tipografias. Com os mapas não era diferente. Basta confrontar os quatro mapas publicados para ilustrar o livro de Barléus com o grande mapa, para percebermos que este último foi enriquecido de detalhes por seu editor. Inúmeras cenas remetem para a vida na América: expedições, guerras, casa de engenho. Ainda que algumas destas cenas apareçam nas gravuras originais, não há dúvida de que foram enriquecidas, fenômeno que ocorre com as edições do próprio mapa mural ${ }^{11}$.

Voltemo-nos, por ora, ao significado geopolítico desta carta, normalmente menosprezado pelos comentários de especialistas, que se concentram na riqueza de detalhes do próprio documento Em primeiro lugar o momento de sua publicação, por volta de 1647, pouco antes da República das Províncias Unidas ser reconhecida como independente no âmbito dos estados europeus com a assinatura da paz de Westfália, pondo fim à Guerra dos Trinta Anos. 0 mapa é eloqüente porque juntaria na mesma superfície a extensão da costa brasileira reivindicada pelos portugueses e destaca a presença neerlandesa naquela parte da América, que foi tomada de Portugal quando este era parte do Império espanhol. Na parte inferior no canto esquerdo uma inscrição qua patet orbis, lema adotado por Nassau, e as alegorias ao redor fazem menção às guerras ${ }^{12}$. É justamente neste canto que está representado o litoral do Brasil. Grande parte dos mapas neerlandeses apontava o limite sul da costa brasileira como a entrada do Rio da Prata, e ao norte, o Amazonas, prática já verificada em mapas e textos elaborados pelos portugueses que disputavam a posse desta área com os espanhóis.

No canto esquerdo do mapa mural (Fig. 2) há uma carta com toda a costa do Brasil, do lado direito há menção à região

11 WHITEHEAD, P. J. P.; BOESMAN, M. Um retrato do Brasil holandês do século XVII: animais, plantas e gente pelos artistas de Johan Maurits de Nassau. Rio de Janeiro: Livraria Kosmos, 1989.

12 Ibid. p. 158. 
dominada pelos neerlandeses, onde se lê Brasilia sob regimine Batavorum. Depois da restauração de 1640, houve intensas negociações entre Portugal e a República e, no âmbito da diplomacia, ficou decidido que os neerlandeses manteriam a posse das capitanias conquistadas. Ainda que Jaime Cortesão possa estar certo no que diz respeito ao fato de que alguns dados registrados na carta tenham sido retirados de documentação portuguesa, considerar apenas o teor artístico do mapa neerlandês torna menos perceptível seu apelo geopolítico: registrar uma possessão da República das Províncias Unidas num ponto estratégico da costa pertencente aos portugueses que ainda disputavam os limites com os espanhóis, particularmente a entrada do Prata ao sul. Estes, por sua vez, eram, no período, uma ameaça tanto para a República quanto para Portugal que recém conquistara sua independência frente à coroa de Espanha.

Finalmente, o mapa é repleto de animais. De onde vieram estas imagens? Qual o sentido delas nos mapas? Voltemos agora ao segundo aspecto que queremos explorar ao observar os mapas, qual seja o de espaço para divulgação de conhecimento e também como meio de difusão da coleção do Conde de Nassau, afora isto, os mapas eram também meios importantes para tornar conhecidos artigos que podiam ser consumidos em mercados de luxo, como, por exemplo, os animais exóticos vindos do ultramar ${ }^{13}$. 0 conhecimento acerca da História Natural se ampliou significativamente com as viagens européias ao Novo Mundo, principalmente no que concerne às informações sobre a flora e a fauna. A descrição minuciosa dos produtos da natureza era em si meio de produção de conhecimento. Texto e imagem eram resultados de observações cuidadosas e também fortes instrumentos de transmissão do saber, ainda mais se os exemplares in natura eram oriundos de terras distantes, e, lembremos, nem todos podiam ser levados para Europa sob risco de não se adaptar e morrer, sejam plantas, sejam animais.

0 cultivo de jardins, que ganhou impulso na Europa Ocidental a partir do Renascimento, tem relação direta com as transformações no campo da cultura científica. Não surpreende que, ao longo do século XVI, os jardins tenham assumido importância crescente no desenvolvimento do estudo da botânica. Transformados, no começo do século XVII, num verdadeiro local de produção do conhecimento, sua construção nas principais

13 SMITH, P. e FINDLEN, P. Merchants and marvels: commerce, science, and art in early modern Europe. Nova Iorque: Routledge, 2002. 
universidades européias tornou-se bastante comum. Esse foi o caso de Leiden, cujo jardim foi inspirado no da cidade italiana de Pádua. 0 lugar, juntamente com o anfiteatro de anatomia, teve importância também para a realização de aulas práticas sobre as propriedades terapêuticas das plantas e dissecações de animais, pesquisas fundamentais para o conhecimento médico naquele momento. É oportuno lembrar que Piso e Marcgrave freqüentaram as aulas de medicina e botânica em Leiden durante os anos 30 do século XVII e é muito provável que esta experiência tenha sido igualmente aplicada ao jardim construído ao redor da residência do Conde de Nassau, várias espécies descritas pelos sábios faziam parte da coleção ali existente. Ainda que este recinto se aproximasse muito mais de um gabinete de curiosidades, recinto que reunia objetos os mais variados, desde elementos da natureza até artefatos.

Afirmamos anteriormente que o Recife-holandês reuniu condições favoráveis à produção de conhecimento. As transformações urbanas sofridas por esta cidade durante o domínio neerlandês já são bastante conhecidas entre os historiadores. Para nós, o que interessa é destacar neste núcleo urbano, o jardim que circundava o Palácio Vrijburg, sede do governo (Fig. 6). Além disto, a vinda de homens como o médico Guilherme Piso, o astrônomo Georg Marcgrave, os pintores Frans Post e Albert Eckhout - para citar apenas aqueles que vamos mencionar ao longo deste trabalho - garantiu um ambiente cultural também favorável à produção de saber. Afora a presença de sábios no próprio Recife-holandês, foi de grande importância o envolvimento de homens que nunca realizaram viagens ao Novo Mundo, mas tinham interesses evidentes no material que delas resultavam. Como por exemplo Johannes de Laet, diretor da WIC e responsável pela primeira edição de História natural do Brasil, de 1648, obra que registrou os trabalhos de Piso e Marcgrave. 0 próprio Laet foi autor de importantes livros sobre a América. Um outro exemplo é o da família Blaeu, proprietária de uma das principais tipografias da época especializada na confecção de mapas foram também os editores do texto de Gaspar Barléus, História dos feitos recentemente praticados no Brasil, de 1647. É evidente que este material, uma vez colocado em circulação por meio dos livros publicados, serviu de base e fonte para a confecção do mapa em questão. A tipografia dos Blaeu teve acesso a alguns originais devido a sua proximidade com a Companhia das Índias Ocidentais e Orientais. Foi também a partir do século XVI que as gravuras conquistaram um potencial de circulação que fez com que elas além de ilustrarem os livros pudessem ser adquiridas. Some-se a isto o fato de que o mercado editorial de Amsterdam 
era um dos mais movimentados à época e era alimentado pelas notícias e novidades oriundas do ultramar.

Voltemos ao mapa. No centro algumas figuras de animais. Observemos o tamanduá, que só aparece no mapa mural e não naqueles que ilustram o texto de Barléus. Comecemos pela descrição do animal oferecida pelo médico Guilherme Piso e publicada no livro por ele organizado em 1658:

Além disso, os frutos de toda espécie e mesmo os cereais do nosso país, com singular fertilidade, realizariam a esperança dos colonos, se pudesse achar remédio geral contra a praga das formigas. [...] Oxalá criasse a Natureza muitas feras devoradoras de formigas, [...] como o fazem os animais quadrúpedes de aspecto estranho, denominados tamanduá, do tamanho de um cão, providos de longas unhas, que, cavando profundamente, descobrem os esconderijos das formigas e logo lhes introduzem sua língua fina, que se estende quase a vinte e sete polegadas; quando ela está coberta de formigas, contraem-na de súbito e engolem-nas, colhidas na armadilha. ${ }^{14}$

A semelhança entre a gravura do livro e a que ilustra o mapa é evidente (Fig. 8). Desde o século XVI as gravuras passaram a fazer parte dos livros de História Natural e tinham um papel central na transmissão do saber. 0 conhecimento sobre os animais e plantas era adquirido através de uma descrição minuciosa. Iniciava-se pelo nome, em seguida eram fornecidos detalhes sobre forma, tamanho e cor. Quando possível, eram evocadas semelhanças entre os exemplares da fauna e da flora já conhecidos pelos europeus. As gravuras não tinham apenas função ilustrativa, mas eram vias primordiais para auxiliar a reprodução o mais fiel possivel do exemplar in natura. A observação atenta da natureza e os meios de representação dos objetos naturais eram etapas complementares na produção de conhecimento sobre o mundo natural.

Após detalhamento da forma dos animais e plantas, eram listadas as utilidades da espécie para a vida do homem, com destaque para os atributos terapêuticos e, como no exemplo do tamanduá, mencionava-se o lugar na ordem da natureza. 0 tamanduá era, conforme suas características, um exímio co-

14 PISO, W. Indiae Utriusque res naturalis et medica (1658). Traduzido e anotado por Mario Lobo Leal, Piso, História Natural e Médica da Índia Ocidental, Rio de Janeiro, Ministério da Educação e Cultura, Instituto Nacional do Livro, 1957. p. 65. 
medor de formigas, praga que atormentava a vida dos colonos no Brasil. A escolha do tamanduá, neste caso muito provavelmente feita pelo editor, entre outros animais para representar o Brasil no mapa não foi acidental, ainda mais se notamos sua presença também no frontispício de História natural do Brasil.

Como dito anteriormente, a presença de pintores e sábios estudando in loco a natureza americana marcou uma especificidade e contribuiu para a extensa produção de conhecimento durante o domínio neerlandês. As pinturas de Eckhout, por exemplo, não podem ser entendidas sem sua relação direta com os estudos da natureza realizados por Guilherme Piso e George Marcgrave. Há uma polêmica em relação à autoria de algumas gravuras que ilustram História natural do Brasil e as pinturas, se são efetivamente de Eckhout ou Marcgrave. Isto se dá sobretudo pela semelhança do resultado. 0 mesmo acontece em algumas ilustrações que trazem a assinatura de Frans Post no livro de Barléus, sobretudo em relação aos animais e plantas que complementam as paisagens. Era comum a repetição das imagens nos livros de História Natural.

Acreditamos que a possibilidade de pintar ao vivo as espécies americanas, como ocorreu com os pintores que viveram no Recife-holandês, contribuiu para que algumas de suas representações tornassem consagradas como modelos. Além de possibilitar a correção:

Vi esse animal vivo (a preguiça) trazido do Brasil; bem parecia com a imagem somente não tinha o pescoço tão longo, como dei na descrição da América, pág. 618, com o nome de Uau. Da mesma maneira também fiz uma descrição com o nome de Hay, lib. XV, cap. 5, mas julgo conveniente avisar que a última figura vinda de Thevet não se acha conforme, embora Gesner, a tenha apresentado, porque o ventre não é tão pendente; as unhas são mais curvas; a cauda, mais curta. Acerca da indolência, a descrição está bastante conforme como pude observar num vivo; morreu, porém, depressa antes que pudesse fazer mais observações. Erradamente Gesner lhe dá o nome de Artopiteco, porque nada tem que ver com os macacos. ${ }^{15}$

Interessante confrontar a gravura da preguiça como era representada (embora o texto aponte para o erro, o livro ainda reproduz a imagem de Gesner - Fig. 9).

15 MARCGRAVE, J. História Natural do Brasil. Trad. Mons. Dr. José Procópio de Magalhães. São Paulo: Imprensa Oficial do Estado, 1942. p. 222. 
Assim, as cenas representadas, as paisagens traçadas, os animais e plantas inseridos no mapa não são simples alegorias, como alguns outros elementos da estampa. Não temos registro que permita reconstituir cada passo tomado por Blaeu na composição de seu mapa Brasília qua parte paret Belgis. Entretanto, sabe-se que uma das preciosidades da casa editorial, o Atlas Mayor, de Wilhem Blaeu, foi composto a partir da reunião não só de mapas que os Blaeu tinham feito a pedido das Companhias das Índias Orientais e Ocidentais, como também de cartas manuscritas e outras informações coletadas pelos editores junto aos arquivos das Companhias e do próprio mercado. Ainda que o mapa seja atribuído a George Marcgrave, não se podem menosprezar as inserções feitas na oficina do cartógrafo.

0 alargamento das fronteiras da República significou, no plano intelectual, a abertura de novos espaços para investigação. A partir de um campo de saber específico, a história natural, os estudos sobre a natureza ganhavam significados que se desdobravam numa apropriação, por parte dos neerlandeses, de territórios distantes: conhecer detalhadamente é também conquistar. Algumas práticas da história natural, como por exemplo a formação de coleções, implicava a coleta de informações e objetos e na posterior organização dos mesmos em um recinto ou em um livro. Foi com essa idéia que buscamos entender o que possibilitou a confecção do mapa de Johanes Blaeu, isto é, a conjugação de esforços de vários indivíduos e diversas instituições, localizados na República ou no Recife holandês.

Enriquecer mapas com animais, plantas e gentes do lugar representado não era apenas um procedimento ilustrativo ou um apelo comercial. Em trabalho magistral, a historiadora da arte Svetlana Alpers já apontou para as relações estreitas entre a arte e a ciência na República das Províncias Unidas durante o século XVII. Parece-me que considerar a contribuição da História Natural (tal qual era praticada antes das inovações introduzidas a partir do século XVIII) nas representações cartográficas é um caminho interessante para dar sentido aos objetos que compõem o mapa, especialmente aqueles característicos do Brasil. 0 modelo de História Natural vigente ainda considerava significativas as ligações orgânicas entre o lugar, o clima, a fauna, a flora e os próprios homens de uma região. Assim como nos textos era comum partir do registro de informações precisas sobre a localização e as características do meio ambiente, nos mapas também eram inseridos elementos que hoje podem nos parecer meramente ilustrativos.

0 que buscamos demonstrar é como o mapa, além de instrumento da conquista territorial, é também um espaço precioso de divulgação de informações sobre as regiões nele represen- 
tadas. Neste sentido, observamos como os conhecimentos acerca de História Natural forneceram um manancial de imagens que podiam ser utilizadas para representarem as diferentes regiões do Novo Mundo representadas nas cartas. No caso específico da experiência neerlandesa na confecção de mapas sobre o Brasil, verificamos que havia uma oferta significativa destes elementos garantida por uma conjuntura favorável às iniciativas de estudo realizadas por sábios holandeses que viajaram sob patrocínio da Companhia das Índias Ocidentais e residiram no Recife durante a administração do Conde João Maurício de Nassau Siegen.

A presença de animais e plantas nos mapas neerlandeses do século XVII, mais uma vez, vai além de simples ornamento ou preenchimento de espaços vazios, desconhecidos, áreas ainda não ocupadas pelos europeus. Como meio de produção e difusão de conhecimento, os mapas além de veicularem informações importantes sobre o lugar, eram produto de uma cultura científica em que se afirmava existirem correspondências intrínsecas entre uma região, seu clima, sua paisagem, sua flora, sua fauna e os homens que nela habitavam. 
Figura 1: PISO, W. e MARCGRAVE, G. Historia Naturalis Brasiliae. Leiden: Franciscus Hack. Amsterdam, Ludovicus Elzevier, 1648.
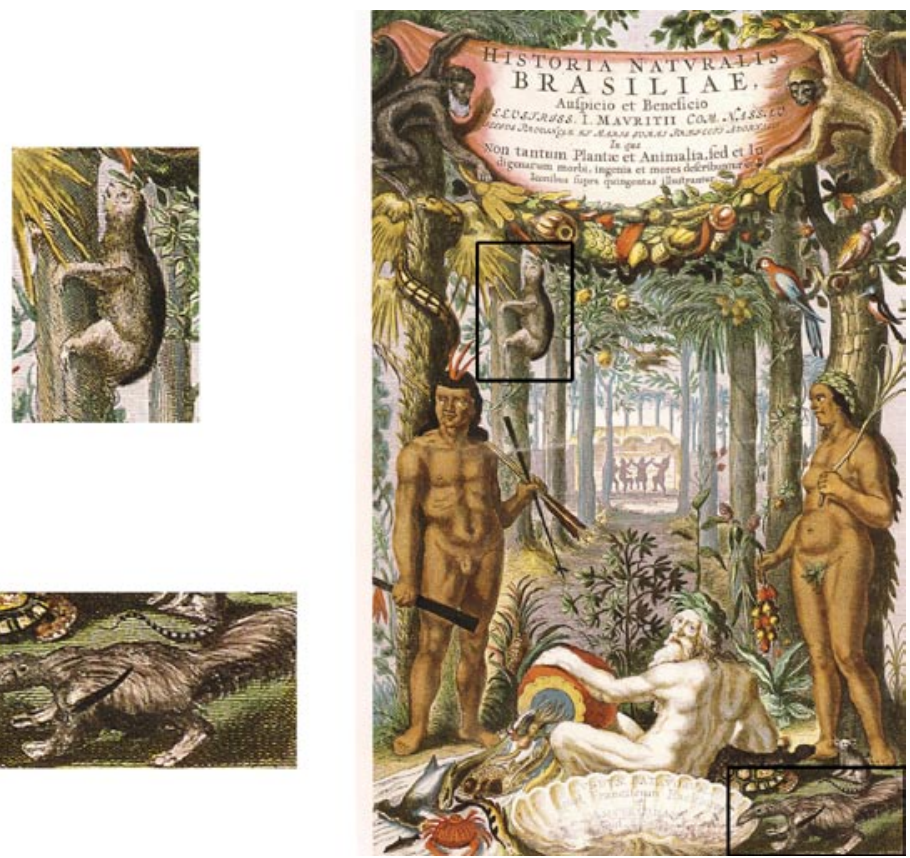
Figura 2: Brasilia qua parte paret Belgis, [...]Brasilia Geographica e Hidrographica Tabula Nova. Contines Praefecturas de Cirii, cum Itapuama de Pernambuca, Itamaracá, Paraiba et Potigi vel Rio Graunde. Quam propriis observationibus ac dimensionibus diuturna peregrinatione a se habitis, fundamentaliter superstruebat et delineabat Georgius Marggraphius Germanus, Anno Christi 1643. Amsterdam, Johanes Blaeu, 1647.

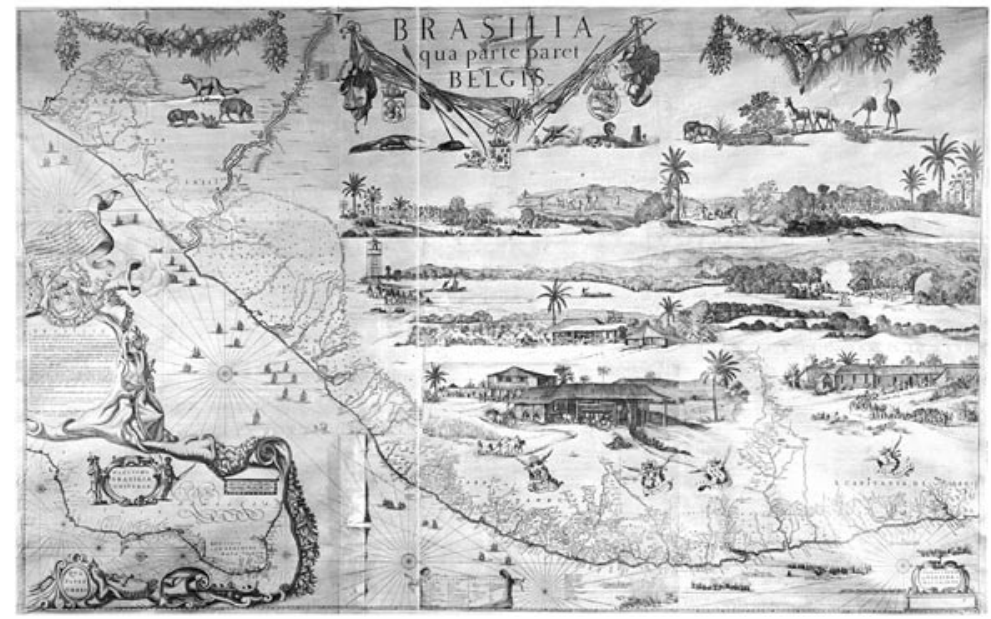


Figura 3: Detalhe em cor. G. Marcgrave. Gaspar Barléus. Rerum per octennium in Brasilia et alibi nuper gestarum, sub praefectura Illustrissimi Comitis I Mauritti, Nassoviae. Amsterdam, loannes Blaeu, 1647.

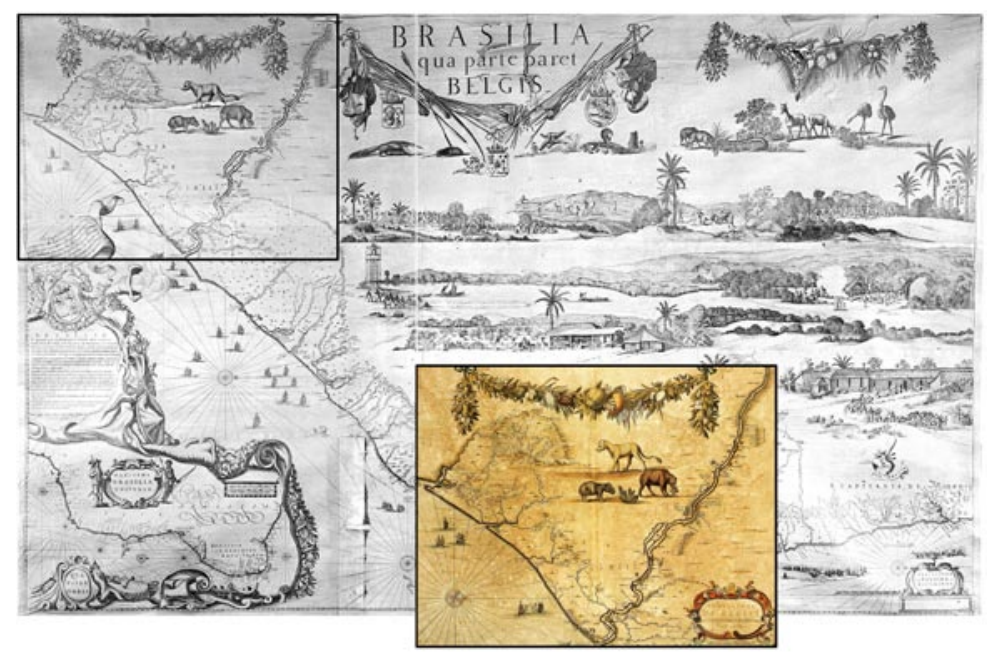


Figura 4: Detalhe em cor. G. Marcgrave. Gaspar Barléus. Rerum per octennium in Brasilia et alibi nuper gestarum, sub praefectura Illustrissimi Comitis I Mauritti, Nassoviae. Amsterdam, loannes Blaeu, 1647.

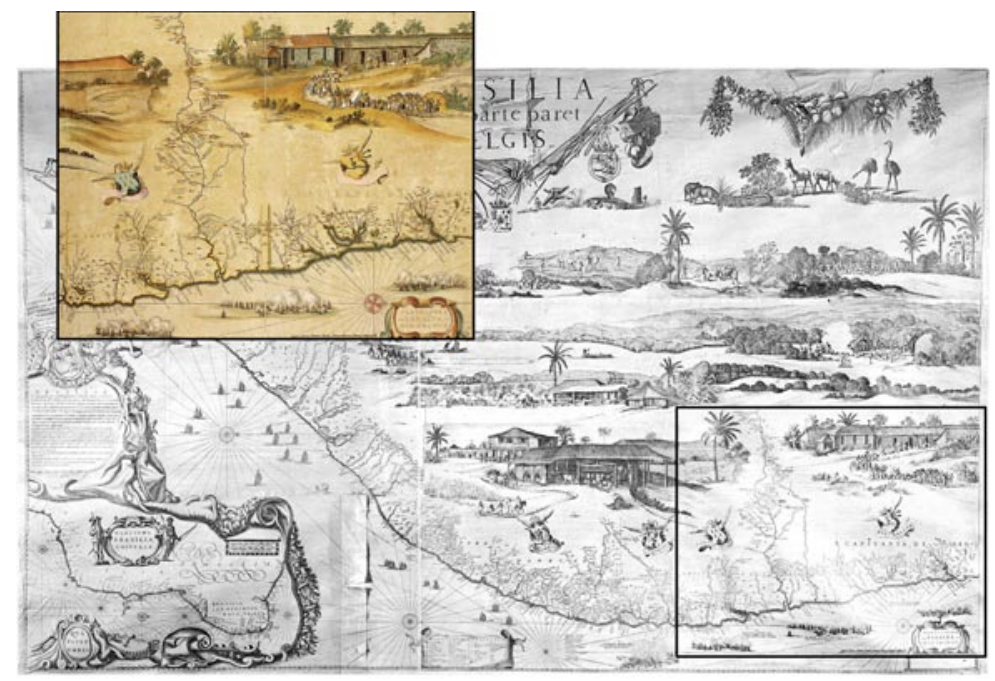


Figura 5: Detalhe em cor. G. Marcgrave. Gaspar Barléus. Rerum per octennium in Brasilia et alibi nuper gestarum, sub praefectura Illustrissimi Comitis I Mauritti, Nassoviae. Amsterdam, loannes Blaeu, 1647.

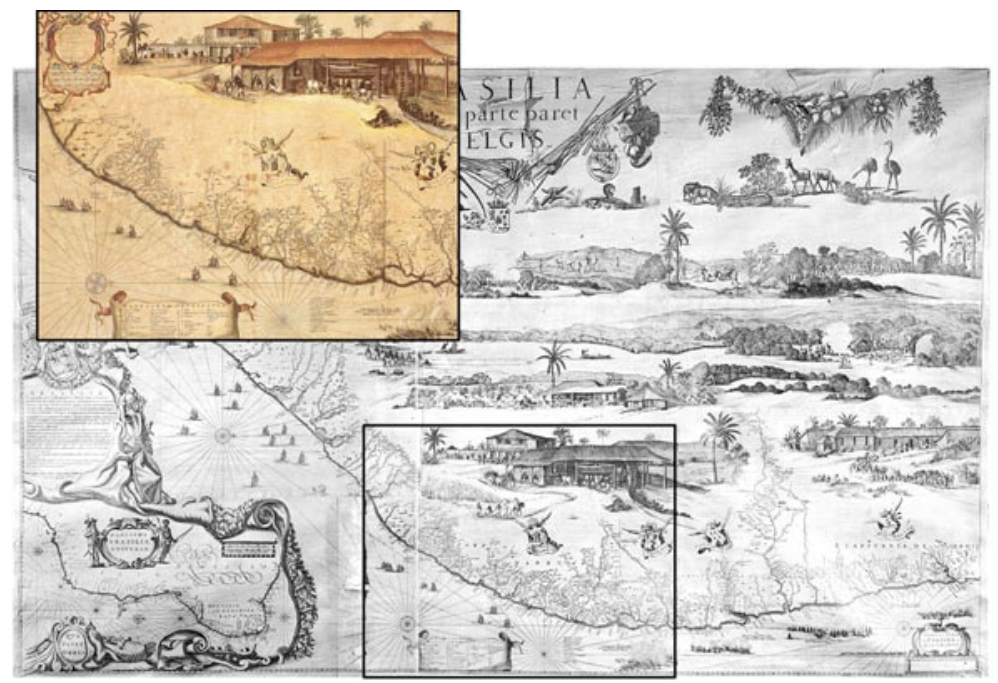


Figura 6: Detalhe em cor. G. Marcgrave. Gaspar Barléus. Rerum per octennium in Brasilia et alibi nuper gestarum, sub praefectura Illustrissimi Comitis I Mauritti, Nassoviae. Amsterdam, loannes Blaeu, 1647.

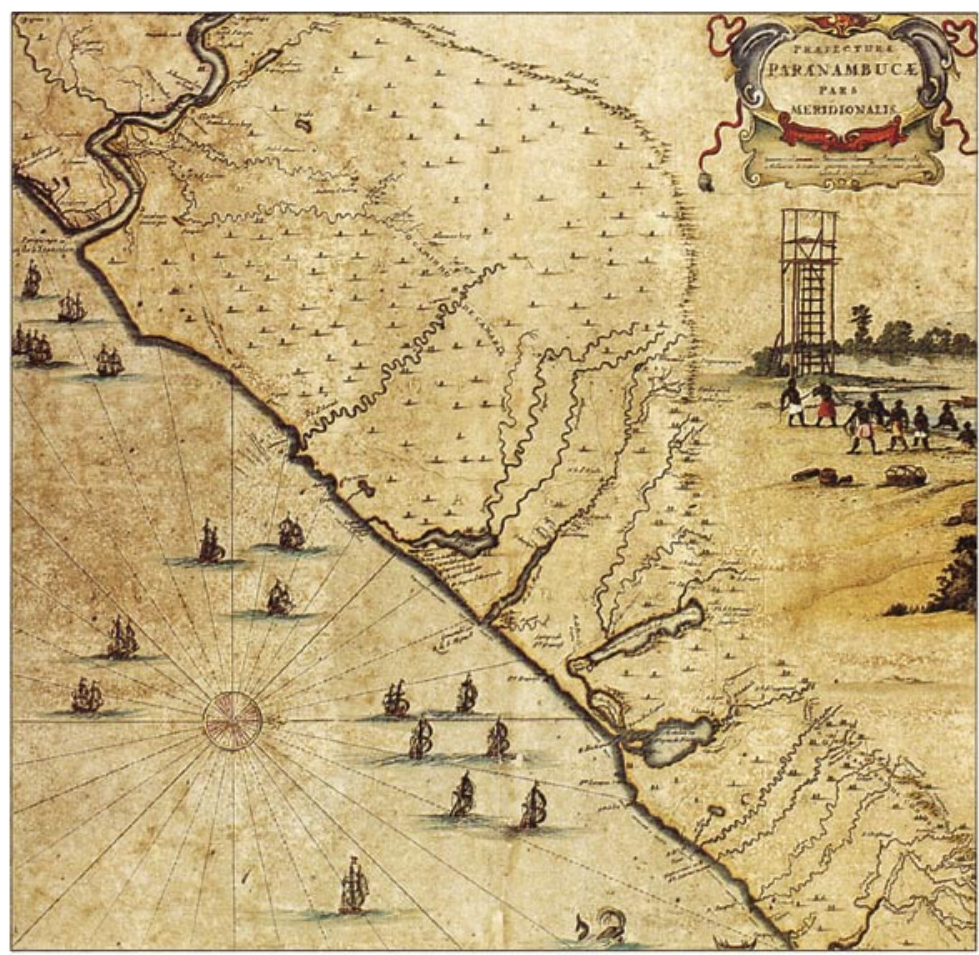


Figura 7: Palácio Friburgo. Gaspar Barléus. Rerum per octennium in Brasilia et alibi nuper gestarum, sub praefectura Illustrissimi Comitis I Mauritti, Nassoviae. Amsterdam, loannes Blaeu, 1647.

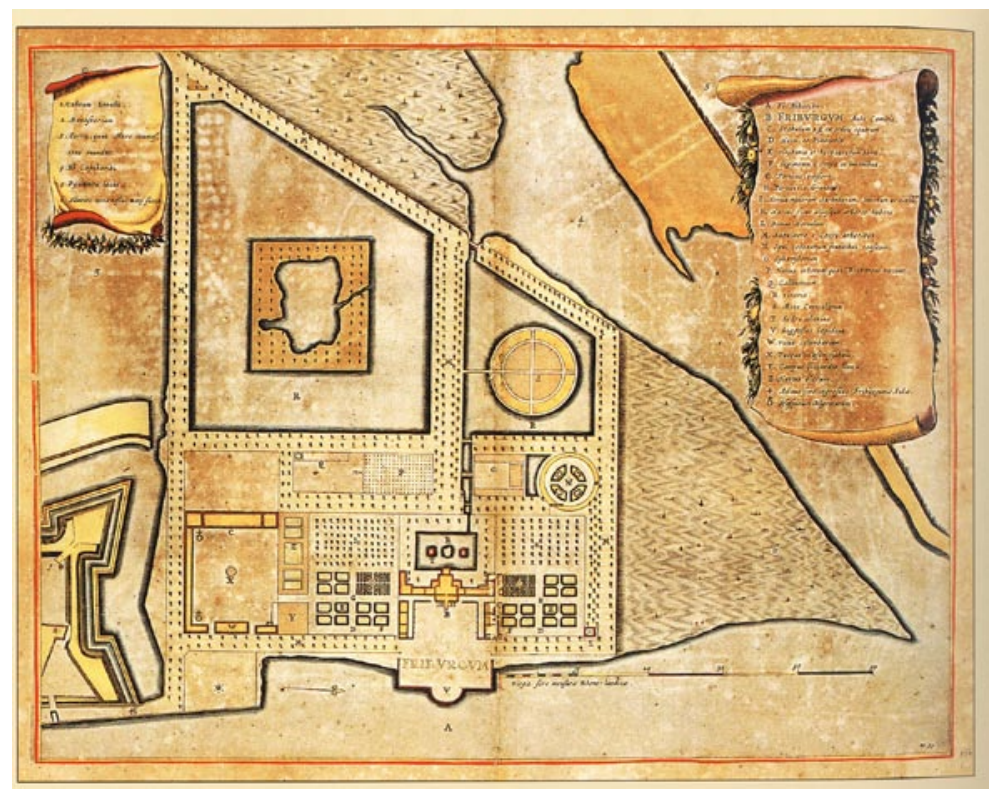


Figura 8: Detalhe do Tamanduá. PISO, W. e MARCGRAVE, G. Historia Naturalis Brasiliae. Leiden: Franciscus Hack. Amsterdam, Ludovicus Elzevier, 1648. 0 mapa ao fundo é o de Blaeu, 1647.

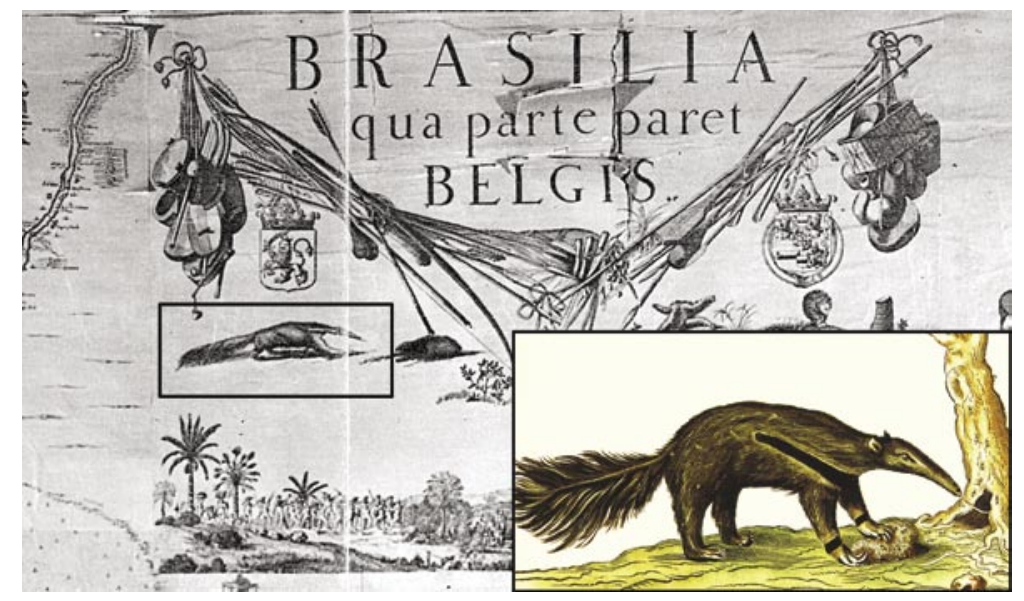

Figura 9: Detalhe da preguiça. No canto esquerdo inferior: PISO, W. e MARCGRAVE, G. Historia Naturalis Brasiliae. Leiden: Franciscus Hack. Amsterdam, Ludovicus Elzevier, 1648. No canto esquerdo superior, imagem atribuída a Albert Eckhout. Theatrum Rerum Naturalium Brasiliae. 0 mapa ao fundo é o de Blaeu, 1647.

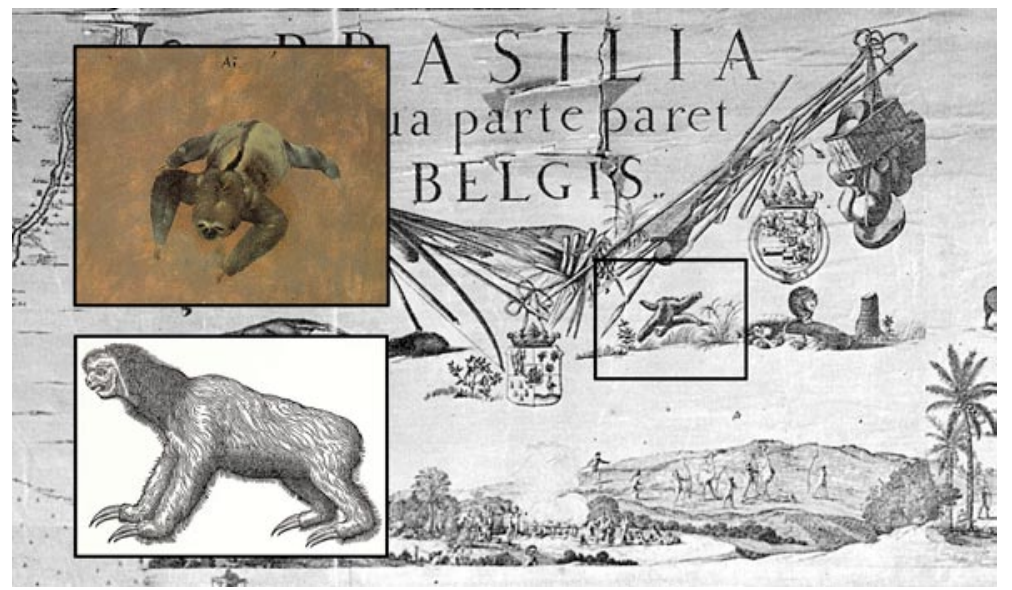

